\title{
Class in the Assamese Film Sandhyarag (1977): An Analysis
}

\author{
Minakshi Dutta $1^{\text {st }}$, Rana Sharma $2^{\text {nd }}$ \\ $1^{\text {st }}$ Department of Cultural Studies, Tezpur University, India \\ $2^{\text {nd }}$ Department of Communication and Journalism, Gauhati University, India
}

\begin{abstract}
Cinema represents a particular class of people with its composition. Thus it helps in the process of naturalization of the existing class differences of society. Assamese film director Dr. Bhabendra Nath Saikia's debut film Sandhyarag(1988) is a systematic documentation of the two existing classes of post- colonial Assamese society- urban middle class and working class. It demonstrates the enduring class difference and exploitation in a coherent manner. How the middle class becomes the reason behind the creation of working class is the main theme of the movie. This paper is an attempt to analyze the way of the director in dealing the above mentioned issues both in cinematic and narrative composition of the film Sandhyarag.
\end{abstract}

Key Words: Assamese Cinema, Middle Class, Working Class, Post-colonial Assamese Society

\section{Introduction: Cinema and Class}

Cinema produces and reproduces cultural signification through representation. The questions of class are ineluctably linked up with cinema. The film production system is based on capitalism and profit making motive and it is naturally bound up with power relations related to issues of class, caste, race and gender. Karl Marx's definitions of class and rethinking of those definitions by scholars like Antonio Gramsci, Louis Althusser, and Herbert Mercuse is common theoretical framework for studying class representation in cinema. Class difference is mainly based in power relations and according to Marx and Gramsci 'cultural artifacts manifest these differences' (Hayward: 2000:60). In explaining the functions of culture, in making sense of those differences, both the scholars established the relationship of class with cultural aesthetics. Marxist theory of class is applied in film studies in four ways- analysis of relationship between the classes within the narrative as well as the cinematic text of the film, the historical and cultural contexts of the production, modes and practices of production and the ideological effect of the product on the audience (Ibid: 61). In cinema, with the application of cinematic tools, class has been ichnographically denoted and the class differences are also brings into focus in front of the spectator. Cinematic tools like clothing, language-register, environment, lighting, camera movement etc. naturalizes class differences and from a medium of entertainment, cinema transformed into an Ideological State Apparatus of Althusser.

In this paper an attempt has been taken to follow the first way among the above mentioned four ways, in studying the award winning movie Sandhyarag (1977) of Assamese film director Bhabendra Nath Saikia. Before examining the projection of class in this particular movie an attempt will be made to describe some key concepts of class in section 1 of this paper. Then in section 2, description is given on the Assamese middle class in particular. Following this, section 3 focuses on the role of middle class in the formation of a new class i.e. the working class. Section 4 will be an analysis of the film Sandhyarag from the above mentioned perspective.

\subsection{Middle Class: Definition and Formation}

The class is an old phenomenon; with the development of human civilization on the basis of socioeconomic and political status, people are divided into some classes and its nature is also going under changes with the time. Class is being defined differently by different scholars from time to time. 'For Marx the concept of class was a totality, in the determination of which the economic situation did play a prominent role, but the ideological and political aspects were also very important in class formation.'(Sharma: 1990:3) Economic condition of a section of people defined its class with certain ideological and political values of their own. Class formation and differentiation plays an important role in the understanding of its definition as well as role in the society. But in the present day context, due to the changing pattern of society, the Marxist concept of social class is not fully applicable and instead of this class a new middle class is emerging with some new characteristics. Nullifying the applicability of Marxist concept of class T. B. Bottomore mentioned about two main classes in society, the bourgeois and the proletariat which can be easily identified, but the boundaries of the middle class cannot be defined so easily. (Bottomore: 1966; Sharma: 1990) From time to time theorist defined Middle class in various ways to suit the changing needs of particular social formations. According to G.D.H Cole, 'middle class implies the notions of a society divided into classes and at least suggests a division into three- upper, middle and lower...' (Cole: 1955; Sharma: 1990) The question of the 'middle class', 
Poulantazas states, 'stands not only at the centre of current debates on the class structure of the imperialist metropolises, but also of debates on the dominated and 'peripheral' formations....It has....assumed a decisive importance, both in the imperialist and in the dominated social formations...' (Sharma: 1990:7)

During nineteenth and early twentieth century, like other colonial country, in India also a new and distinct class emerged 'in a luminal arena between the colonial state on the one hand and traditional elites on the other.' (Fernandes: 2006) In one article Ian Ball says, 'The highly educated middle and upper classes in India, once embarrassed at being 'westernized' and for speaking and thinking in English, are feeling confident in their sense of identity- and their language for the first time....This is a new money class' (Chadha: 2006:1-4). In her book India's New Middle Class: Democratic Politics in an Era of economic Reform, Leela Fernandes also mentioned about three characteristics of the new middle class in the colonial period. Firstly, this class can be marked by the access of certain socio-economic resources like English education and modern forms of professional employment (ibid). Secondly, the newness of this class lies on the public representativeness within the realm of democratic civic life. And finally, this claim of representation was continually accompanied by a project of self identification that was marked by a politics of distinction from both the colonial state and more marginalized social groups. The British Educational policy created a new class of people in colonial India which can be recognized as the new Indian Middle Class. 'The colonial administrator believed that this educational policy would lead to the creation of a class, Indian in blood and color, but English in taste in opinion.' (Fernandez: 2006) But there are certain differences between the old middle class (during colonial period) and new middle class (post colonial period) and these differences are mainly because of its 'relationship with the state'. The old middle class were participated in the anti colonial struggle and the new middle class 'exerts its moral and political leadership over the state through its support for policies of economic liberalization, marketization, and consumption. (Chatterjee: 2008; Ray and Qayum: 2009) Education plays an important role in middle class society. 'For the average middle class person, however, education was the only means to move upwards and maintain, if not widen the distance from those at the bottom of the ladder eking out a living from menial labour' (Varma: 2007: xxii). There is always an effort for uplift their position to the upper class. Social hierarchy is well accepted by both the upper and lower section of the society. Their socio-political position is preordained by the social structure and 'if opportunity arises to break out of a preordained slot, it must be seized against the opposition of others through individual effort, and for personal gain' (Varma: 2007: xxvii). One important feature of this section of people is marked by Pavan K. Varma in his book The Great Indian Middle Class. He said that the notions of public good played no role in life of the middle class people. 'The rich in India have always lived a life quite uncaring of the ocean of poverty around them' (ibid). And it is interesting to note that when the people of lower class able to upgrade their position they also do the same to those left behind.

\subsection{Assamese Middle Class}

The evolution of the Assamese middle class, as a social category, has been traced to the feudalbureaucratic (Gohain, 1973) or feudal-tribal (Guha and Das, 1974) social settings of the pre-British times, which however, acquired much of its typical characteristics during its confrontational engagements with the practices of education, trade and commerce, and the bureaucracy of the British regime. Because of its historical position which has been something like of the petty-bourgeoisie, a term preferred by Guha and Das to describe this class, the Assamese middle class had never been a complete owner of the systems of production, yet they have been enjoying a considerable access and control of the resources of production. This ambiguity of their structural position has been keeping this class at distances from both the productive proletariat and the bourgeoisie owners. Thus, the middle class is simultaneously seen to be the follower, the critic and the victim of the prevailing social system, but obviously they remained handicapped in bringing out any significant radical change in the system.

Because of their active and enthusiastic participation in the spheres of institutionalized education and other state apparatus, the middle class segment emerged as a culturally more visible category. It is therefore not surprising that their values, worldviews and judgments began to be strongly represented in the creative fields of Assamese literature, art and cinema of the twentieth century. While scholars like Gohain has rightly warned about the 'dangers in discussing the Assamese middle class in general', a set of characteristics can be perceived as typical to the Assamese middle class, at least in the context of their representation in the above mentioned creative fields. This would include the conflicting middle class mindset with issues of tradition and modernity, and the local and the global. In her Doctoral thesis Manorama Sharma had tried to establish a connection of the urban middle class with rural society. She said that though 'A middle class is usually seen as urban phenomenon, but in the case of Assam the middle class was not a rootless urban class, but a class which had roots and links with the rural sector of the society' (Sharma: 1990:141).

Scholars studying the characteristics of Assamese middle class have noted that the elite or intellectual section of Assamese society always refrains from asking the 'disturbing questions' related to the hypocrisy and contradictions of the Assamese Middle class (Gohain: 1975, Mahanta: 2009, Sharma: 1991). They are happy 
with the material and superficial wealth and prosperity that could be enjoyed by a selective few amongst themselves and remain always optimistic towards imagined virtues of western modernity and urbanity. However, they are seen to be giving a blind eye towards the in-built faults and conflicts in the orthodox middle class values which are being preserved uncritically even in the changing contexts of urbanization and industrialization.

However, from 70s to 90s, in Assamese film industry directors like Padum Barua, Bhabendra Nath Saikia, Jahnu Barua, Manju Barua etc. had decided to focus on the issues related to the Assamese middle class in their cinemas. The entire oeuvre of B.N. Saikia is a documentation of the rise and development of Assamese middle class people. He had mainly emphasized on the issues like woman suppression, class exploitation, changing social values and changing familial values under the wave of urbanization.

\section{Creation of the Assamese Middle Class - The Working Class}

'Writing about Victorian England', Leonore Davidoff argues that 'social divisions are most clearly revealed in the reproductive sphere, and thus the household should constitute a primary unit of analysis....paid domestic work within the household bridges the private-public divide, bringing social relations of power (class, caste, race/ethnicity, gender) into the household, and mirroring and reproducing these relations within the domestic unit' (Baviskar and Ray: 2011:249). Keeping household servant is an important feature of a middle class family. The main task of the household works includes the cooking, cleaning and child care 'involve turning the raw into the cooked, dirt into cleanliness, and disorder into order' (ibid, 250). These activities draw a line between the employer and the servant which leads to the creation of these two sections of the people in society. In Davidoff's words, 'housework is concerned with creating and maintaining order in the immediate environment.....the most important part in the creation of such an order....making clear boundaries between them' (ibid). Those who are free from these boundaries enjoy the higher position in the society. Therefore 'to be middle class is to distance oneself from work on the boundaries of purity and pollution' (ibid). In one of her article Swapna Banerjee said that 'as the role of the housewife became more and more elaborate and complicated, combining the manifold functions of a nurturing and sacrificing mother and dutiful wife, there was an increase in the employment of domestic service in the last two decades of the nineteenth century' (Banerjee: 2004:37). The women folk of middle class families are fully dependent on their housemaids for their day to day work and this tendency helps to create another section of people in the society subordinate to them, which can be termed as working class. This group of people is not connected by 'biological ties' with the employers but who becomes the part and parcel of their life for their day to day life. According to Seemin Qayum and Raka Ray, 'Bengali middle class employers enact the immutability of class through their words and labor practices at home, their ordering of space, their refusal to engage in manual work, their assumptions of control over other people's labor.....they create naturalized inequalities in 'modern' forms to constitute themselves as appropriately modern middle class Indians' (Baviskar and Ray: 2011:270).

Like the other parts of India, during the colonial and post-colonial period, a class of people visibly emerged in the Assamese society also, and scholars recognized this class as the middle class section of Assamese society. They are called differently by different scholars like, feudal- bureaucratic, bhadralok (Gohain'1973) petty-bourgeoisie or feudal tribal (Guha and Das, 1974) and they had a special position in the socio-economic, cultural and political scenario of Assam. This social category had never been a complete owner of the systems of production, yet they have been enjoying a considerable access and control of the resources of production. This ambiguity of their structural position has been keeping this class at distances from both the proletariat and the bourgeoisie owners. Thus the Assamese middle class is simultaneously seen to be the follower, the critic and the victim of the prevailing social system, but obviously they remained handicapped in bringing out any significant radical change in the system. May be due to geographical location, there are some similarities between the Middle class of Assam and Bengal. The Middle class of Bengal were known as Bhadralok and 'this term is multivalent but means most of all 'respectable people' (Ganguli-Scrase: 2003:551). The people of Bengali middle class were well behaved and well cultured with urban professional occupation. Like the middle class of other parts of Indian Bengali Middle class people are also the follower of Western culture and values. As Banerjee in her article, Down Memory Lane: Representation of Domestic Workers in Middle Class Personal Narratives of Colonial Bengal described how the Bengali Middle class women are responsible for the creation of a new section in the society; same reason is applicable for Assamese society also. The new middle class of Assam is mostly dependent on the servants and it leads to the development of a new fraction in the society.

\section{Dr. Bhabendra Nath Saikia and his film Sandhyarag}

Writer and dramatist, Dr. Bhabendra Nath Saikia (1932-2003) has been one of the few prolific and serious film directors from Assam who earned his distinction in film-making through his seven Assamese films, namely, Sandhyarag (1977), Anirban (1981), Agnisnan (1985), Kolahal (1988), Sarathi (1991), Abartan (1993) 
and Itihaas (1996) and two Hindi films namely Kalsandhya(1999) and Darpaharan. Each one of this handful of collection earned positive responses from both the general audience and critics. Amongst the various features about Dr Saikia's film-making, one thematic characteristic that is overtly visible in all his films is the attempt to depict, often critically, a world of the Assamese middle class population of the post-independent times of a newly urbanized and industrialized Assam. Born in Nagaon district of Assam, his love for film blossomed in his University days at Calcutta (now Kolkata). At that time he was highly influenced by Bengali and Hollywood movies. And maybe this was one of the important reasons for choosing serious style of filmmaking by this genius. He had done his $\mathrm{PhD}$ in Physics from London University in 1961. He had started his career as a Physics teacher at Sivsagar College and then at Gauhati University. He had written a good number of novels, stage drama, short stories and children literatures in his lifetime. He received Sahitya Academy Award in 1976 and Padma Shri in the year 2001. He died on August 2003. Yves Thoraval in his book The Cinemas of India mentioned that 'Bhabendranath Sakia, along with Jahnu Barua, is the architect of the entry of Assamese cinema into art house cinema' (Thoraval: 2000: 428). Except Kalsandhya and Darpaharan, all other films were able to win National Award. His films discussed in detail- the struggle against poverty, the transcending of human society and its various constrains on humanity, protest against patriarchy, death of human aspirations, dilemma of life etc. National film critic Utpal Dutta in his article Filmmaker Dr. Bhabendra Nath Saikia mentioned that 'through his stories, Dr. Saikia portrayed the humane face of the middle class in our society, the manifold emotions of this class - their happiness or sadness, rights and wrongs, fulfillments and losses-all came through his lucid writings in a broad perspective, with a unique style solely belonged to him.' (Borpujari) And these feelings are clearly reflected in his adapted films i.e. Sandhyarag, Anirban, Agnisnan, Kolahal, Sarathi and Itihaas also. In all his films he is noted to address critically a set of social issues. Usually, women always take special positions in his films. Eighteen years of his works can be considered as a critical assessment of postindependence Assamese society.

His debut film Sandhyarag (1977) is based on his own short story Banaprastha (1969). It's 'a polemical look at the urban-rural divide, middle class character and irony of changing attitudes towards lifethrough which Assam assured its place in the 'proverbial parallel cinema movement' of the country' (Borpujari and Kalita:2007:xix). Utpal Datta considered Sandhyarag as a 'critical analysis of the socio-economic dilemmas in a different cinematic platter' (ibid: 2007:89). Compared to his other films this film was widely received by reviewers and audiences of the mid seventies. With this film Saikia had shown a significant advance in serious filmmaking in Assam as he 'got instant national recognition and international attention' (ibid: xix).During his lifetime he had produced seven Assamese film and all of them are based on middle class ethos and aspirations. Each and every film of Dr. Saikia was shot at real location, using real houses, roads and markets to represent the actual situation of the society.

Like the other films his film Sandhyarag is also not above criticism. 'Lake of economy', 'flat and toneless ending', 'patchy music' (Sharma: 2001:67-70) etc are some of the loopholes pointed out by the Assamese film critic Apurva Sharma. According to him, this was the first film by the director and therefore he is unable to capture the filmic language fully and besides this as this is an adapted version of his short story he is unable to keep the balance between the two medium of expression (Ibid: 66). The narrative is based on the exploitation of the middle class section and as the director is also a member of that class, his middle class sympathy, feebleness and pain is clearly reflects in the film.

Many critics criticize that the ending of the film is not clear; director has not given any solution for the problem raised by him. At the end, the director had tried to give a solution with Saru's surrender to the impotent driver, Moti and according to Apurva Sharma, it weakens the screenplay. Along with this the exploited nature of the middleclass is also not obvious. There is no doubt that their poor economy forces them to choose the life of housemaid not the middle class. But it is also true that the middle class people can help them to survive.

The film is from the point of view of the two housemaids. Through their eyes, the director had given a picture of middle class ethos and values. The film is about their struggle for survival and their move towards new ray of hope. In the film the director had explored the reasons behind the acceptance of this kind of life by these two housemaids. The narrative of the film clearly draw a line between the two sections of the Assamese societyurban/rich and rural/poor. Though these two belongs to the opposite side of the quantum, they are fully dependent on each other. And this interdependence, which is only for labor and economy, becomes more prominent in this film. The poor for their survival and the rich for a luxurious life depend on one another. The differences among these people in respect of their treatment are clearly expressed in the film.

\subsection{Representing Class}

The film Sandhyarag defines the 'middleness' of Das' family through the eyes of Saru (the housemaid) and portrayed the sufferings she and her sister Taru, who is also a housemaid of another middle class family, had to face for survival. The film dramatized two parts of their life- at the house of their employers where they enjoy the lavish life with the family and at the last part of the film after returning from that life they are facing 
problem in their poor and miserable life. Showing the changing condition of the female protagonist, the film marks the distance between the two sections of people. It is true that the reason behind the oppressing economic condition of the protagonist is some unseen force rather than individualized villains but there is enough ground for the middle class families to make the maid's life easy going, which they didn't perform. Thus the director openly criticized the middle class values through his film. In the film, the middleclass enjoys a secure position in the society; real struggle occurs at the opposite side of the quantum. Their behavior and enjoyment of facilities in the household clearly shows the differences prevail in between them. Saikia uses detailed décor to demarcate the social and economic distinctions between Saru and her employer. Saru's house, dress and her hesitating look exemplifies her poverty and on the other side, well-furnished living and dining rooms, food habits, dressing style clearly shows the prestigious position of Das' family. At the same time, the film is careful to distinguish the treatment of their employer to them. In one scene the director shows that after serving the guest nothing is left for Saru to eat and Mrs. Das is also not conscious about this. They used to give the servants their used cloths to wear and store room to sleep. And with this kind of activities the director is able to show the behavior of the middle class people.

From the beginning, the director had tried to create a separate world to visualize the two sections of the society. The film starts with the death of protagonist's father, which compelled the family to go to market to survive on selling vegetables. It is noteworthy to mention that Saikia defies the typical cinematic construction of 'the rural' by showing paddy fields or so, but he opens his rural world through a scene of a rural market, which seems to be a conscious attempt to make a prelude for an economic tension between the rural and the urban. The director shows the urban world through the window of a bus on her first trip to the 'town'. With the noises of buses and vehicles, visuals of electric tower, crowded markets, telephone posts, smoking factories and multistoried buildings, Saikia impressively creates the new Assamese urban world of post-independence times. Likewise, when Saru entered to her employer's house at first she saw Kanta (daughter of her employer) wearing a costly frock. Here the director had incorporated a point-of-view shot of Saru to Kanta, which indicate her first encounter with the elite class. Das and his son are also introduced to the audience with a scene where the father taught his son English word and meaning. As we had already mentioned that the middle class people are supporter of English education and therefore the director is fully successful in introducing the members of an Assamese middle class family. Symbolically also the director is successful in drawing a line between the members of two classes. When Saru arrived at Das' house, Kanta told her mother about Saru's arrival moving towards the window. She saw her through the window and with the use of window the director shows her future position in the family. Perhaps the director uses the window to indicate the way of looking at the working class people by an agent of the urban middle class. The relationship or distinction between these groups of people is not so clear at that period. Though the servants are biologically not tied with their employer, even they can't become professional regarding their service. Dr.Saikia represents the initial stage of the 'servant keeping practice'. Therefore, the people, especially the working class people are unable to maintain the professional relationship with their employer, which now a day becomes clearer.

The film is careful to distinguish the lower position of Saru from the privilege position of Das' family. This distinction is easily understandable for the audience by the detailed representations of clothing, décor, and other consumer goods. In the encounter scene the camera movement from one character to another clearly portrayed the distinction between Saru and Das' family. Saru's hesitation to talk with the family members, her ways of standing shows her position in the family. With some minor activities the director tries to show how the middle class people treat the lower class people. When Moti (the driver) asks Saru for drinking water and Saru brings it in a glass, Mrs. Das asks her to use a separate glass for him. This shows how much they keep themselves away from that section of people. Even in one scene the director shows how a housemaid is forced to sacrifice her childhood desire. Kanta and her friends forced Saru to play with them, she agreed and when she tried to enjoy her childhood Mrs. Das called her to do some work. Her position in the family is just like the bird of a cage, whose happiness is ruined for someone's luxury.

Saikia's camera techniques achieve realism in a special way. With the use of close-up and medium long shots, the director clearly conveys subtle nuances of emotion. The close-up of the material details in the film from Saru's POV shot are used to signify her assigned task and also the status symbol of the family. In his film he mostly captures his actor's subtle and powerful expressions in medium close-ups in such way that it enables the spectator to understand the essence of the scene. The film clearly criticizes the hypocritical nature of the middle class people. Only because of this selfish nature Saru and Taru has to go through the crucial stages of their life. Because of the absence of 'biological ties', the employers are not concerned with the future of their servants. After sending Saru to her home, Mr. Das and his family never contact her. Even his lecture in the meeting shows the distinction between his activity and its expression in a social gathering. Here he says about humanity, about the beauty of life, connection with the common people and their sentiments etc. etc. whereas in reality for their own benefit they had spoiled the life of a small girl. 
Male member's attitude towards the female maid is also an important aspect of this film. The female maids are sexually harassed by the middle class men. In the film, Taru was tried to molest by her employer's son and instead of taking any action against the boy his mother blame her for this. The housemaids are both economically and sexually exploit by their Maliks. Such a character of the middle class male is included in his last film Itihaas (1996), where the protagonist has to face many such problems to survive in an urban middle class world as a part time maid and ultimately she has to commit suicide. The film Sandhyarag reveals both the ways in which economic condition shape gender role and identities and in which men and women experience the treatment differently even within the same family and society. This distinction creates two sections in the society and the position of male and female is also different in these sections. The male members of the middle class family are not concerned with the family matter; they fully depend on their wives and housemaids. In the narrative neither the 'men' nor the 'women' come under same group with similar functions and positions. There are vast difference between the women of middle and working class. According to Fredrick Engels, 'the middle class woman is totally dependent on her husband and is therefore her property. The women of working class participating in the production in a way challenge their exploitation' (IGNOU study material of DWED). In Sandhyarag, Mrs. Das and her daughter Kanta is fully dependent on Saru. Though they are independent to take the household decisions, the final consent comes from the male members. In the encounter scene the director clearly signified the position of Mrs. Das in the family. When she comes outside to see Saru, she chooses the stool instead of the chair to seat. In Assamese culture the elderly persons are always given the higher sitting position to show respect and with this activity she shows that her position is lower than her husband who, after a while comes and occupied the chair. They are busy with cutting, knitting etc just to pass their leisure time. But on the other hand representative of working class woman, Saru's mother is able to take the whole responsibility of her family; she goes to market for selling vegetables to earn money which shows her independent nature.

As the protagonist of the film is a female, question may arise if it is a feminist film or not. Partly we can say yes to this question, because it is a film about the exploitation of women labor and her life. But interestingly the exploiters are not the male, but a class of people. The film through the protagonist's eyes beautifully depicted the gender role of the male and female members of the society. Therefore, it is an unconscious gender representation by the male director, who is also a member of the same gender ridden society. Domestic situations and female centrality also expose the feminist perspective of the film.

\subsection{Solution for the Catastrophe}

Sandhyarag is a film about the ongoing crisis of the working class people where the character of the middle class is also become prominent. With this film the director had raised a question in front of the audience. At the end of the movie Saru asked Moti to take her with him. Knowing about Moti as an impotent man, she accepts him only for food and shelter; she wants to live her future life as a human not as a slave. Perhaps, this is the solution given by the director. But this is not the ultimate solution for such problem. All of them, Saru, Taru and their mother want to come out from the crisis with the help of an impotent person. Use of an impotent person can also signify the hollowness of their trial. It may show that this section of people can never get a chance to uplift their position or may be by such ending the director tries to show the flow of the rural society towards urbanization. Moti is symbolized as an agent of urban society, who wants to buy a new taxi to become independent. Here the director shows the possibility of up gradation of the working class agents to middle class status.

If poor and helpless female servant can survive by marrying a wealthy man, as per the narrative of the film, than what should a male servant do for his survival? Therefore, the solution given by the director is not suitable for all situations.

But the director is fully successful in giving a symbolic representation of the end results of the narrative. With two or three dialogue Saikia shows that along with Saru, Taru and her mother is also in a hope to go with her. They just want to come out from their poverty, which is going to kill them within a short period. Taru agree to do all her household work only in a condition of not calling her a maid. And their mother wants to go with her to help her during her pregnancy. Then some ray of sun comes to their house through their broken wall and with it the director ends the film giving an indication of a new life.

Saikia's film is crucially linked to the changing shape of the Assamese middle class: a move from an "old middle class" of small, independent property owner (merchant, farmers and feudal lords) to a "new middle class" of salaried workers. In this film he has closely criticized the middle class values of urban world. The people of this group are more hypocritical and selfish in nature which is clearly showed in the film. The film is a juxtaposition of the urban as well as the rural life. At the same time Dr. Saikia's commitment to depict the problems of the common people and standard of projection give him a special position in the film world. 


\section{Conclusion}

From 1950s, in the Indian film history, a new consciousness of realist filmmaking was emerged among the filmmakers like Satyajit Ray, Ritwik Ghatak, Mrinal Sen, Shayam Benegal, Govind Nihalani etc. They tried to utilize cinema as a medium for social change. With this purpose in their mind they had depicted some sensitive issues with realist cinematic treatment. In her article Zara Hatke (somewhat different): The New Middle Classes and the Changing Forms of Hindi Cinema Rachel Dwyer mentioned that before the 'rehabilitation' to cultural capital of Hindi cinema in the 1990s, one of the sharpest divides over culture was the way that this cinema was seen through the lens of class, and these divisions were often along the lines of realism. She opined that realist film such as those of Shyam Benegal were concerned with caste, class and gender, while Govind Nihalani made films about corruption and the struggle to remain human in such settings. Films of Dr. Saikia come under Benegal's category. Like Benegal style of filmmaking, Saikia had also focused on society from class, caste and gender perspective, and it creates a place for him in the family of Indian parallel filmmaker.

\section{References}

[1] Banerjee, Swapna M. "Down Memory Lane: Representation of Domestic Workers in Middle

Class Personal Narratives of Colonial Bengal”. Journal of Social History:37(2004)

[2] Baviskar, Amita and Raka Ray (Ed) (2011) Elite and Everyman: The Cultural Politics of the Indian Middle Classes. Routledge . NewYork

[3] Borpujari, Manoj and Dr. Garima Kalita.(2007) Perspectives On Cinema Of Assam. Gauhati Cine Club. Guwahati

[4] Chadha, Neha "The Middle Class: Consuming and Consumed the Romance of Bombay Cinema" Journal of Moving Image (2006): $1-4$

[5] Dwyer, Rachel (2011) 'Zara hatke!: The New Middle -Classes and the Segmentation of Hindi Cinema.in Donner, Henrike, (ed.), A Way of Life: Being Middle-Class in Contemporary India London:Routledge. Pp184-208.

[6] Fernandes, Leela (2006) Indian middle Class: Democratic Politics in an era of Economic Reform. University of Minnesota

[7] Ganguli, Ruchira and Scrase, Paradoxes of Globalization, Liberalization, and Gender Equality: The Worldviews of the Lower Middle Class in West Bengal, India, “Gender and Society" 17(2003): 544-566, Accessed 23/05/2012

[8] Gohain, Dr. Hiren “ Origin of the Assamese Middle Class" Social Scientist.2.1 (1973):1-26

[9] Guha, Amalendu and Arvind N. Das “Origins of the Assamese Middle Class: A comment" Social Scientist 4.67 (1974):59-66

[10] Hayward, Susan (2000) Cinema Studies: The Key Concepts. $2^{\text {nd }}$ Ed. London: Routledge

[11] Parchesky, Jennifer "Lois Weber's The Blot: Rewriting Melodrama, Reproducing Middle Class" Cinema Journal 39.1 (1999): 2353

[12] Sharma, Apurva (2001) Asomiva Chalachitrar Cha Aru Pohar. Durgacharan Pujari Smriti Nyash, Guwahati

[13] - (2012) The Lone Ranger In a Forsaken Frontier: The Unsung Pioneer of Indian Cinema in the North-East, Guwahati :Aank-Baak

[14] Sharma, Manorama (1990) Social and Economic Changes in Assam: Middle class Hegemony. Ajanta Publication

[15] Thoraval, Yves. (2000) The Cinema of India (1896-2000) New Delhi: Macmillan Press

[16] Varma, Pavan.K. (2007) The Great Indian middle Class. New Delhi: Penguin Books 